\title{
The Relationship between Personality Types and the Cognitive - Metacognitive Strategies
}

\author{
Nadia Soleimani \\ Department of Psychology \& Educational Administration \\ Shahid Beheshti University, Tehran, Iran \\ Morteza Nagahi (Corresponding author) \\ Department of Industrial \& Systems Engineering \\ Mississippi State University, Starkville, MS, USA \\ Tel: 1-562-221-2007_E-mail:mn852@msstate.edu \\ Mohammad Nagahisarchoghaei \\ Department of Infrastructure \& Systems Engineering \\ North Carolina University at Charlotte, Charlotte, NC, USA
}

Raed M. Jaradat, PhD.

Department of Industrial \& Systems Engineering

Mississippi State University, Starkville, MS, USA

Received: March 5, 2018 Accepted: April 12, 2018 Published: May 1, 2018

doi:10.5296/jse.v8i2.12767 URL: https://doi.org/10.5296/jse.v8i2.12767

\begin{abstract}
This study investigates the relationship between the personality type and cognitive-metacognitive strategies utilized by test-takers in reading comprehension tests. One hundred undergraduate Iranian English Foreign Learning (EFL) students participated in a reading comprehension test followed by a questionnaire and the Myers \& Briggs Type Inventory. The questionnaire consisted of 30 cognitive-metacognitive items (Phakiti, 2003). These questions inquired about the thought process that occurred while completing the test.
\end{abstract}


The 93-item Myers-Brigs Type Indicator (MBTI) questionnaire is a tool that provides individuals with a personality type. The study employed a quantitative data analysis where the input data was analyzed in two ways. First, descriptive statistics were used to describe the sample characteristics, and then a two-way ANOVA was calculated to obtain a general view of the relationship between the variables. The data analysis resulted in the identification of 14 personality types along with three groups of readers distinguished by their reading comprehension test scores as highly successful, moderately successful, or unsuccessful. However, the results suggested that there were no significant relationships between personality types of test-takers and the cognitive-metacognitive strategies utilized during a reading comprehension test. Using a 90 percent Confidence Interval (CI), there was meaningful interaction between the personality traits (Extroversion/Introversion and Judging/Perceiving) of Iranian EFL test-takers and their use of cognitive-metacognitive strategies.

Keywords: personality types, cognitive and metacognitive language use strategies, Second Language (L2) reading, TOEFL (Test of English as a Foreign language), undergraduate EFL students. 


\section{Introduction}

Some form of test may be administered whenever information is needed to help make decisions in regard to assisting people in selecting courses of action pertaining to their future educational or occupational status (Aiken, 1991). One of the most dreaded parts of school life has to be the class test. All through school, students are required to take tests (Saches, 2009). However, when the focus is on English Foreign Learning (EFL) language testing, due to the complex nature of language and language learning, the importance of test taking seems more significant. Traditionally, teachers focus primarily on the tests results (scores) to determine comprehension (Cohen, 1998). However, since the 1970s, those proctoring these tests have been encouraged to pay more attention to the processes utilized by the respondents in answering language tests. The concept is to consider the processes that the test takers exercise in efforts to produce acceptable answers to questions or tasks while remaining cognizant to the perceptions they have about these questions and tasks prior, during, and post response. This information is used for two purposes: 1) test development and 2) interpretation of test results (Cohen, 1998). With regard to the interpretation of test results and decision-making, teachers should be more cautious and pay attention to different factors, which may contribute to the test takers' performance. These factors include test takers' personal characteristics, i.e., individual attributes that are not part of the test takers' language ability but may influence their performance on a language test (Bachman \& Palmer, 2010). Many attributes may contribute to the performance of the test-takers such as age, gender, native language, educational background, foreign language aptitude, socio-psychological factors, personality, ethnolinguistic factors, multilingual ability attitudes, motivation and others (Bachman 1990). However, among all these attributes, the personality types of test takers along with their language learning strategies are of paramount interest to the researcher in the present study. Many teachers instruct students who are very competent in understanding and doing the assignments throughout the whole term. When it reaches the test time, these students are occasionally unsuccessful. Instructors may also have students who have a recorded better test performance than in-class performance. Why do these students perform in such a manner? Is trend at all related to the individuals' characteristics or personality? In regard to the increasing interest in further analyzing test takers' characteristics that may influence language test performance, this study focuses on investigating the relationship between test takers' personality types and the cognitive-metacognitive strategies utilized in the reading section of the TOEFL test.

\section{Literature Review}

Language researchers have long held an interest in factors that may affect individuals' performance and scores on language tests. Bachman (1990) proposed a model to investigate the effects of three types of systematic sources of variability on test scores: 1) communicative language ability, 2) personal characteristics of test takers, and 3) characteristics of the test method or test tasks. Bachman argued that the second factor, the test-taker characteristics, include a variety of attributes such as age, gender, native language, educational background, attitudes, motivation, anxiety, learning strategies, and cognitive style (Song and Cheng, 2006). Lowie, van Dijk, Chan, and Verspoor (2017) and Culver (2016) stated that success in 
learning a second language is strongly affected by a set of relevant characteristics ranging from the age language learning is initiated, aptitude, and personality.

Over the last four decades, several researchers focused on the results and scores of second-language assessment validation through the determination of test reliability, the inter-correlation of subtests, the relationships between tests or criterion variables, and the effects of different test methods. However, there is a lack of research germane to the examination of the respondents' behaviors while they take the tests. Since the early 1970s, the focus of research concerning foreign language learning and teaching has shifted from the methods of teaching to the influence of learners' characteristics on the process (Purpura, 1997; Tajedin, 2001).

A wide range of personal characteristics could affect the solutions devised and the decisions we make throughout the test (Jaradat, 2015; Jaradat et al., 2017a). Although there are several personal characteristics that could potentially affect test performance, the focus of this study is on personality types and language use strategies (i.e., test taking strategies). For more details, readers can refer to the works of (Biedroń \& Pawlak, 2016; Bui 2017; Jaradat \& Pinto, 2015; Jaradat et al., 2017b; Pawlak, 2012; Rashtchi \& Afzali, 2016; Trammell, 2016).

\section{Personality Types}

Personality types refers to the psychological classification of different types of individuals. Personality typing is a way by which one's preferences in life and doing activities are analyzed. The concept of personality types goes back to the Swiss psychologist Carl G. Jung (1921). Katharine Briggs and her daughter Isabel expounded upon Jung's work and developed his theories further to develop the Myers-Briggs personality types. The Myers-Briggs personality types have served as a popular means of characterizing individuals' personality traits in both the classroom and the workplace (Lawrence, 1994). The best way to describe the Myers-Briggs Type Indicator (MBTI) is as an instrument, the purpose of which is to measure psychological preferences on four different scales:

1) How one prefers to be energized;

2) What one prefers to pay attention to;

3) What one initially bases a decision on; and

4) How one prefers to manage his/her life.

The four pairs of preferences or "dichotomies" are:

1) Introvert - Extravert - Preferred Source of Energy: Introverts (I) are generally introspective and energized by spending time alone. Introverts also tend to internalize their thoughts or focus on the inner world of ideas whereas extraverts (E) thrive in a group setting. Extraverted minds seek external activity and interaction.

2) Sensing - Intuition - What One Pays Attention to: Sensors (S) prefer to gather information through experience and are attentive to details while intuitors $(\mathrm{N})$ prefer abstract concepts, are innovative, and are easily bored by details. 
3) Thinking - Feeling - A Basis for Decision Making: Thinkers (T) rely on objective rationalization to make decisions and are considered to be impartial. Feelers (F) are more likely to make subjective decisions based on social considerations rather than strict logic.

4) Judging - Perceiving - Preferences for Managing One's Life: Judgers (J) are typically orderly people who prefer rigid structure and planning but may ignore facts that do not fit their plan or structure. Perceivers $(\mathrm{P})$ do little planning and work spontaneously but are more open to facts that do not conform to their views (Myers, McCaulley, Quenk, and Hammer, 1998).

According to Myers-Briggs, individuals use all four cognitive functions, however, one function is generally used in a more frequently and with greater confidence. The combination of these four scales will result in the 16 personality types; ISTJ, ISTP, ISFJ, ISFP, INTJ, INTP, INFJ, INFP, ESTJ, ESTP, ESFJ, ESFP, ENTJ, ENTP, ENFJ, and ENFP. When these aspects of preferences are combined, they provide a way for us to understand and describe motivations. We all naturally use one mode of operation within each category more frequently than the other mode of operation; this mode is considered a preference. The combination of the four "preferences" defines our personality type (Myers et al., 1998).

\section{Language Use Strategies}

Language testing researchers tend to look at strategies utilized on the tests as opposed to focusing on learning strategies in attempts to explain score variation on specific language tests. Researchers focus primarily on the strategies utilized during the test as they are directly related to the test score variation. Cohen (1998) defined second language (L2) use strategies as one of the components of test taking strategies. He defined the language strategies as steps or actions that learners consciously select in order to accomplish language tasks. According to Cohen, second language (L2) use strategies include: 1) retrieval strategies, 2) rehearsal strategies, 3) cover strategies, and 4) communication strategies. Cover strategies are those strategies that learners use to create the impression that they have control over material when they do not.

Phakiti also (2003) defined these strategies as methods learners intentionally employ to enhance their performance. In a Target Language Use (TLU) situation, the strategies utilized are related to the ongoing working memory in association with the long-term memory to retrieve necessary declarative knowledge (knowing what), procedural knowledge (knowing how) and conditional knowledge (knowing when) from the long-term memory to solve a difficult task (Gange, Yekovich, \& Yekovich, 1993). Using Bachman and Palmer's (1996) model of language abilities, Phakiti (2003) defined metacognitive strategies as test takers' deliberate mental directing and control over their cognitive processing of potential strategies to determine what is necessary for a successful performance. Metacognitive strategies help the test takers: a) allocate resources to the current task; b) determine the order of steps to be taken to complete the task; and c) set the intensity or speed at which one should work on the task. Phakiti (2003) mentioned that cognitive strategies are test takers' ongoing mental activities exercised in pursuit of individual language and world knowledge application to solve the given task. 


\section{$\triangle 1$ Macrothink}

There has been some valuable research on the relationship between personality type and language learning strategies (Ehrman \& Oxford 1989; Carrell, Prince, \& Astika, 1996), but few studies have investigated the relationship between test takers' characteristics and performance on EFL tests. For example, Kunnan (1994) investigated the influence of two major Test-Taker Characteristics (TTCs), social milieu or cultural background and exposure or previous instruction. The investigation studied Test Performance (TP) on tests of English as a Foreign Language (EFL) for two native language groups, the non-Indo-European and the Indo-European. Data from eight countries of the Cambridge-TOEFL comparability study was used. Modeling of the TTCs and the TP factors generally supported an equal influence factors model along with intervening factors type model for both groups.

Carrell et al., (1996) conducted a study on the relationships between the personality types (determined by MBTI) of the individuals of a group of English as a Foreign Language (EFL) students $(N=76)$ at a university in Indonesia and their various measures of their academic performance in a semester-long course which included a series of EFL language measures. Results showed that these EFL students were almost evenly divided between Extraverts and Introverts, with over 50 percent of the students being one of two (out of 16 possible) types: ESTJ (37 percent) or ISTJ ( 21 percent). The distribution of types for these EFL students is similar to those found in similar studies with students of English as a Second Language (ESL) (Cohen, 1998; Chastain, 1988; Biedron \& Pawlak, 2016). Although extraversion and introversion are related to vocabulary and composite course scores, there are few other direct relationships between learners' personality types and their language performance.

Phakiti (2003), in his study, examined gender differences in cognitive and metacognitive strategy use in the context of an EFL reading comprehension test. Three hundred and forty-eight Thai university students took a multiple-choice reading comprehension test, and then completed a questionnaire inquiring of the strategy each participant utilized. Males and females did not differ in their reading comprehension performance or use of cognitive strategies. Interestingly, males reported significantly higher use of metacognitive strategies than females. Within the same achievement groups (highly successful, moderately successful, and unsuccessful), there were no gender differences in either reading performance or use of cognitive and metacognitive strategies.

This study attempted to investigate the relationship between personality type of Iranian EFL learners and their cognitive metacognitive language use strategies on the reading section of the TOEFL test. To fulfill the purpose of the study the following research questions were formulated:

H1: Is there any relationship between personality traits of Extroversion/Introversion and the score of cognitive and metacognitive questionnaire?

H2: Is there any relationship between personality traits of Sensing/Intuition and the score of cognitive and metacognitive questionnaire?

H3: Is there any relationship between personality traits of Thinking/Feeling and the score of cognitive and metacognitive questionnaire? 
H4: Is there any relationship between personality traits of Judging/Perceiving and the score of cognitive and metacognitive questionnaire?

\section{Method}

\section{Participants}

One hundred Iranian university EFL students, aged 21-37, participated during the academic year of 2010-2011. To ensure each participant had passed all General English courses, all the participants were either juniors or seniors. Through a stratified sampling, we considered the initial step in homogenizing group composition. However, participants were homogenized more appropriately into three different groups of highly, moderately, unsuccessful readers, determined through the TOEFL reading comprehension test results. After filtering the dataset based on incomplete survey results, 70 were included in the analysis.

\section{Instrumentation}

The MBTI is one of the most widely used psychological tests (Hughes, 1994). In this study the Persian translated version of Form M, the latest version of MBTI, was used which is a 93-item, self-report questionnaire that takes about 45 minutes to complete. The Cognitive and Metacognitive Strategy questionnaire was adopted from Phakiti (2003). The questionnaire consists of 30 questions on a 5-point Likert scale, 19 of which investigates metacognitive strategy utilization and the remaining 11 questions determines the cognitive strategies used. The time needed to complete the questionnaire ranged from approximately 10 to 15 minutes. Finally, the TOEFL Reading Comprehension Test consisted of the reading section of TOEFL passages (three passages) followed by 30 multiple-choice items each approximately 300 to 400 words in length.

\section{Procedure}

Data was collected through the administration of three passages from the TOEFL. The participants had 45 minutes to answer the reading comprehension test. Each participant was informed that their teacher aimed to assess their general English comprehension as junior and senior students. Participants were informed about the purpose of the research after completing the reading comprehension test. The participants were then asked to complete the 30-item cognitive metacognitive strategy use questionnaire. The questionnaire inquired of how they had completed the reading comprehension task and what they had done while they were taking the test. After these two subsequent assessments, the participants took the 93-item MBTI questionnaire and their answers were collected and scored.

\section{Results}

To investigate the relationship between the variables of the study, descriptive statistics, two-way ANOVA, and the Levene Test were performed (Ahmadi et al., 2014a; Ahmadi et al, 2014b; Nagahi et al., 2018). Prior to discussing the findings, it is appropriate to discuss the MBTI administration results and present the characteristics of the Iranian EFL learners' sample distribution. 
Table 1. The Frequency of Personality Types

\begin{tabular}{cccccr}
\hline $\begin{array}{c}\text { Personality } \\
\text { Type }\end{array}$ & Frequency & Percentage & Personality Type & Frequency & Percentage \\
\hline ESTJ & 18 & 25.7 percent & ISFJ & 4 & 5.7 percent \\
ESFJ & 7 & 10 percent & ISTP & 4 & 5.7 percent \\
ISTJ & 7 & 10 percent & ESFP & 3 & 4.2 percent \\
ESTP & 5 & 7.1 percent & ENTJ & 3 & 4.2 percent \\
ENFJ & 5 & 7.1 percent & ENFP & 2 & 2.8 percent \\
INTJ & 4 & 5.7 percent & ENTP & 2 & 2.8 percent \\
INFJ & 4 & 5.7 percent & INTP & 2 & 2.8 percent \\
\hline
\end{tabular}

Table 1 shows the frequency of each personality type. None of the participants found to have an ISEP or INEP personality types. The ESTJ group has the highest percentage, followed by ESFJ and ISTJ. The ESTP and ENFJ occurred most frequently with each at 7.1 percent followed by INTJ, INFJ, ISFJ and ISTP groups, altogether, with each at 5.7 percent. ESFP and ENTJ groups both with 4.2 percent each followed in frequency. Finally, ENFP, ENTP, and INTP are the least represented groups each having 2.8 percent frequency.

The mean score of the reading test was 18 out of 30 with a standard deviation of six (See Table 2). Based on their scores, participants were divided into three groups; highly successful readers, moderately successful readers, and unsuccessful readers. In total, there were 11 unsuccessful readers, 46 moderately successful readers, and 13 highly successful readers.

Table 2. Descriptive Statistics for Reading Comprehension Test

\begin{tabular}{lccccc}
\hline Reading Performance Level & Score Range & N & Mean & Std. Deviation & Total \\
\hline Unsuccessful & $0-12$ & 11 & & & \\
Mod-successful & $13-23$ & 46 & 18 & 6 & 70 \\
High-successful & $24-30$ & 13 & & & \\
\hline
\end{tabular}

Using the Likert scale, the participants who marked the frequency occurrence as "always" for all the items would obtain 55 and 95 for cognitive and metacognitive strategy use, respectively. On the other hand, a participant who marked frequency as "never" for all the items would obtain 11 and 19 for cognitive and metacognitive strategy use, respectively. However, none of these four extremes were observed in the study. The lower and upper bounds of cognitive strategy use were calculated as 27 and 47, respectively, while 43 and 86 were the lower and upper bounds for metacognitive strategy use.

Since it was difficult to run statistically acceptable analysis on this amount of multiple variable data (reading performance (3 levels)), strategy use (cognitive - metacognitive), and 
personality type (16 types), to investigate any possible relationship among them, the main research question and hypothesis was broken into four sub-questions and sub-hypotheses.

\section{Research Question 1}

H1: Is there any relationship between personality traits of Extroversion/Introversion and the scores of cognitive and metacognitive questionnaires?

A two-way ANOVA used to investigate the relationship between the variables. The F-observed value for the interaction between the personality traits Extroversion/Introversion and cognitive and meta-cognitive sections of the questionnaire is 3.81 (Table 3). This amount of F-value at 1 and 136 degrees of freedom is lower than the critical value of F, i.e., 3.91. Based on the results, there was no meaningful interaction between the personality traits and cognitive and meta-cognitive sections of the questionnaire at 95 percent Confidence Interval (CI). As a result, the first null hypothesis of the study was supported. However, the $p$-value is slightly greater than significant level threshold as 0.053 , is only slightly greater than 0.05 , proving that at 90 percent $\mathrm{CI}$ there is a significant relationship.

Table 3. Descriptive Statistics for Reading Comprehension Test

\begin{tabular}{|c|c|c|c|c|c|}
\hline \multicolumn{6}{|c|}{$\begin{array}{l}\text { Tests of Between-Participants Effects Dependent } \\
\text { Variable: Cognitive/Metacognitive }\end{array}$} \\
\hline Source & Type III Sum of Squares & df & Mean Square & $\mathrm{F}$ & Sig. \\
\hline Extravert/Introvert & 57.417 & 1 & 57.417 & .684 & .410 \\
\hline Question & 641.805 & 1 & 641.805 & 7.642 & .006 \\
\hline Extravert/Introvert Question* & 320.236 & 1 & 320.236 & 3.813 & .053 \\
\hline Error & 11421.963 & 136 & 83.985 & & \\
\hline Total & 632524.942 & 140 & & & \\
\hline
\end{tabular}

\section{Research Question 2}

Is there any relationship between personality traits of Sensing/Intuition and the scores of the cognitive and metacognitive questionnaire?

The result of two-way ANOVA (See Table 4) showed that the F-observed value for the interaction between the personality traits of Sensing/Intuition and the cognitive and meta-cognitive sections of the questionnaire was 0.058. This amount of $F$ at 1 and 136 degrees of freedom was lower than the critical value of F, i.e., 3.91. Based on the results there was no meaningful interaction between the personality traits and cognitive and meta-cognitive sections of the questionnaire. As a result, the second null hypothesis of the study was also supported. 


\section{Ml Macrothink}

Table 4. Two-way ANOVA between Personality Traits of Sensing and Intuition

Tests of Between-Participants Effects Dependent Variable:

Cognitive/Metacognitive

\begin{tabular}{lccccc}
\hline Source & Type III Sum of Squares & df & Mean Square & F & Sig. \\
Sensing/Intuition & 38.998 & 1 & 38.998 & .451 & .503 \\
Question & 417.220 & 1 & 417.220 & 4.827 & .030 \\
Sensing/Intuition Question* & 5.053 & 1 & 5.053 & .058 & .809 \\
Error & 11755.565 & 136 & 86.438 & & \\
Total & 632524.942 & 140 & & & \\
\hline
\end{tabular}

\section{Research Question 3}

Is there any relationship between personality traits of Thinking/Feeling and the scores of the cognitive and metacognitive questionnaire?

Table 5. Two-way ANOVA between Personality Traits of Thinking/Feeling

\begin{tabular}{lccccc}
\hline \multicolumn{5}{c}{ Tests of Between-Participants Effects Dependent } \\
Variable: Cognitive/Metacognitive & & & \\
\hline Source & Type III Sum of Squares & $\mathrm{df}$ & Mean Square & $\mathrm{F}$ & Sig. \\
Thinking/Feeling & .137 & 1 & .137 & .002 & .968 \\
Spacing Question & 395.199 & 1 & 395.199 & 4.556 & .035 \\
Sensing/Intuition Question* & 1.427 & 1 & 1.427 & .016 & .898 \\
Error & 11798.051 & 136 & 86.750 & & \\
Total & 632524.942 & 140 & & & \\
\hline
\end{tabular}

The result of two-way ANOVA (Table 5) showed that the F-observed value for the interaction between the personality traits of Sensing/Intuition and the cognitive and meta-cognitive sections of the questionnaire was 0.016. This amount of $F$ at 1 and 136 degrees of freedom was lower than the critical value of F, i.e., 3.91. Based on the results there was no meaningful interaction between the personality traits and cognitive and meta-cognitive sections of the questionnaire. As a result, the third null hypothesis of the study was supported.

\section{Research Question 4}

Is there any relationship between personality traits of Judging/Perceiving and the scores of the cognitive and metacognitive questionnaire? 
Table 6. Two-way ANOVA between Personality Traits of Judging/Perceiving

Tests of Between-Participants Effects Dependent

Variable: Cognitive/Metacognitive

\begin{tabular}{lccccc}
\hline Source & Type III Sum of Squares & df & Mean Square & F & Sig. \\
Judging/Perceiving & 210.916 & 1 & 210.916 & 2.539 & .113 \\
Question & 102.648 & 1 & 102.648 & 1.236 & .268 \\
Judging/Perceiving Question* & 292.911 & 1 & 292.911 & 3.527 & .063 \\
Error & 11295.789 & 136 & 83.057 & & \\
Total & 632524.942 & 140 & & & \\
\hline
\end{tabular}

The result of two-way ANOVA (Table 6) showed that the F-observed value for the interaction between the personality traits of Sensing/Intuition and the cognitive and meta-cognitive sections of the questionnaire was 3.52. This amount of $F$ at 1 and 136 degrees of freedom was lower than the critical value of F, i.e., 3.91. Based on the results there was no meaningful interaction between the personality traits and cognitive and meta-cognitive sections of the questionnaire and, the fourth null hypothesis was supported. However, the $p$-value is slightly greater than the significant level threshold as 0.063 is only slightly greater than 0.05 , proving that a significant relationship exists in 90 percent of CI

\section{Conclusions and Suggestions}

Two personality types, ISFP and INFP were not found among the Iranian EFL students who participated in this research. These two personality types share two similar personality preferences, feeling and perceiving. ESTJ was found to be the most frequent personality type among the student population followed by ESFJ and ISTJ. In other related Iranian studies, it was also found that ESTJ, ESFJ, and ISTJ were the most dominated personality types among student population (Nosratinia, 2011). This may suggest that these three types of personality are typical of Iranian EFL students, but this would require further investigation and future studies to support such claim. The observed lower percentage of perceiving scale vs. judging scale that addresses the way in which individuals manage their lives may have affected the way students answered the questionnaire or their overall educational status. As those found to exercise the judging personality trait most frequently have a pre-planned, structured, and well-organized ways of life, it is likely that the participants were university students, all of whom have passed the university entrance exam ${ }^{1}$ to attend colleges and universities in Iran. Experience may also have benefited these individuals characterized under the judging personality trait. Having been well-organized and pre-planned might result in their success in the university entrance examination. Similar results were found in Carrell, Prince and Astika's study (1996) on Indonesian EFL students.

Results show no significant relationship between personality type of EFL students and their use of cognitive metacognitive strategies on a reading comprehension test using 95 percent CI. However, there is a significant relationship in the 90 percent CI (p-value 0.057), 
suggesting a correlation between energy level of EFL participants and their use of cognitive metacognitive strategies on a reading comprehension test does exist.

It was shown that extroverts' mean score on cognitive strategies was higher than introverts' mean score (66.38 vs. 61.89$)$ while introverts metacognitive mean score was higher (69.51 vs. 67.69) than extroverts' metacognitive mean score. The difference, although not significant, may be attributed to the different preferred source of energy by these two groups. Extroverts prefer mostly the outer world while their counterparts prefer the inner world of thoughts and experiences.

In the category of sensing and intuitive personality types, the mean score of individuals with sensing preferences for both cognitive and metacognitive strategies was higher (65.26 and 68.57) than those with intuitive preference (63.71 and 67.84). Those with a sensing personality type were found to utilize more strategies than those with intuition preference.

On the third scale (thinking - feeling), the difference between the two groups is very trivial. Both groups used more metacognitive strategies than cognitive strategies.

Finally, there was no significant relationship in the 95 percent CI between personality scale (Judging/Perceiving) of Iranian EFL students and their use of cognitive metacognitive strategies on a reading comprehension test. On the other hand, using a 90 percent CI, there is a low correlation between managing preferences of EFL students and their use of cognitive metacognitive strategies on a reading comprehension test.

${ }^{1}$ All Iranian students need to take the national university entrance exam in their major of study. Then, they will be sorted based on the score they achieved in this comprehensive exam. The highest score among all participants in each major of study get the first rank; second highest score gets the second rank, and so on. The participants with higher rank have a greater chance of admitted to colleges and universities than lower rank participants.

Individuals found to have a preference towards the judging personality trait achieved mean score of cognitive strategies (64.65) which was lower than individuals found to have a preference towards the perceiving personality trait (65.15). In contrast, judgers had a mean score of (69.91) in their metacognitive strategies utilization, which was a higher score than that of their counterparts (63.80). This result is similar to the result of the first scale. This may be attributed to the fact that judgers like to have a planned and organized way of living, so they can take the advantage of planning and monitoring components of metacognitive strategies.

Although no relationship was found between the students' personality types and their cognitive and metacognitive reading comprehension strategy use in 95 percent CI, it can be claimed that those with introversion and judging preferences in their personality types (ex. INTJ or ISFJ) may use metacognitive strategies more, no matter what their two other preferences are (NF, SF, NT or ST). 
The result of the present study might shed some light on the field of foreign language learning, specifically language testing, regarding the factors that might influence test performance. Since strategies are teachable, and this study has concluded that an individual's personality type does not have significant influence on their strategy use, teachers can help all of their students to excel on tests by practicing the application of appropriate strategies in various test sessions.

In acknowledging some limitations of the present study, certain suggestions can be made for further research. It is clear that the questionnaire data employed in this study cannot provide an ideal reflection of mental processing; Moskowitz (1986) recognized that self-reports such as questionnaires leave a lot of room for 'response biases'. According to Paulhus and Reid (1991), questionnaires involve "a systematic tendency to respond to a range of questionnaire items while focused on a bias other than the specific item content" (p. 307). For example, people often respond in a way that presents them in a more favorable light, even if these responses do not reflect how they actually think or behave ('Enhancement and denial in Socially Desirable Responding'; Paulhus and Reid, 1991). Another limitation of the study was the inadequate number of questionnaire items. The types of cognitive and metacognitive strategies mentioned in the questionnaire were a few of the possible strategies students may have utilized during the reading test. As such, caution needs to be exercised in discussing and generalizing the findings. Further research with a larger and more diverse group should be conducted to determine whether these results can be replicated.

\section{References}

Ahmadi, S. A. A., Azar, H. K., Sarchoghaei, M. N., \& Nagahi, M. (2014a). Relationship between Emotional Intelligence and Psychological Well Being. International Journal of Research in Organizational Behavior and Human Resource Management, 2(1), 123-144.

Ahmadi, S. A. A., Tajabadi, S. H., Nagahi, M., \& Sarchoghaei, M. N. (2014b). Effect of Leader-Member Exchange on Perceived Organizational Support. International Journal of Research in Organizational Behaviour and Human Resource Management, 2(1), 98.

Aiken, L. R. (1991). Psychologicaltesting and assessment. 7th Edition. Boston : Allyn \& Bacon.

Bachman, L. F. (1990). Fundamental considerations in language testing. Oxford University Press.

Bachman, L.F. and A.S. Palmer, (1996). Language Testing in Practice. Oxford University Press.

Bachman, L.F. and A.S. Palmer, (2010). Language Assessment in Practice. Oxford University Press.

Biedroń, A., \& Pawlak, M. (2016). The interface between research on individual difference variables and teaching practice: The case of cognitive factors and personality. Studies in Second Language Learning and Teaching, 6(3), 395-422. https://doi.org/10.14746/sllt.2016.6.3.3 
Bui, N. H. (2017). The Relationship Between Self-Efficacy and Perceptions of Different Literacy Types Among College Students. Journal of College Reading and Learning, 47(1), 45-57. https://doi.org/10.1080/10790195.2016.1218808

Carrell, P. L., Prince, M. S., \& Astika, G. G. (1996). Personality types and language learning in an EFL context. Language Learning, 46(1), 75-99. https://doi.org/10.1111/j.1467-1770.1996.tb00641.x

Chastain, K. (1988). Developing second language skills. Theory and practice, $3^{\text {rd }}$ Edition. Florida: Harcourt Brace Jovanovich Publishers.

Cohen, A. D. (1998). Strategies in learning and using a second language. New York: Longman.

Cohen A. D. (2006). The coming age of research on test taking strategies. Language Assessment Quarterly. 3(4), 307-331. https://doi.org/10.1080/15434300701333129

Culver, T. F. (2016). Increasing Reading Compliance and Metacognitive Strategies in Border Students. Journal of College Reading and Learning, 46(1), 42-61. https://doi.org/10.1080/10790195.2015.1075447

Ehrman, M., \& Oxford, R. (1989). Effects of sex differences, career choice, and psychological type on adult language learning strategies. The modern language journal, 73(1), 1-13. https://doi.org/10.1111/j.1540-4781.1989.tb05302.x

Gange, E. D, Yekovich, C. W., \& Yekovich, F. R. (1993). The Cognitive Psychology of School Learning. Boston, MA: Little Brown.

Jaradat, R. M. (2015). Complex system governance requires systems thinking-how to find systems thinkers. International Journal of System of Systems Engineering, 6(1-2), 53-70. https://doi.org/10.1504/IJSSE.2015.068813

Jaradat, R. M., \& Pinto, A. C. (2015). Development of a framework to evaluate human risk in a complex problem domain. International Journal of Critical Infrastructures, 11(2), 148-166. https://doi.org/10.1504/IJCIS.2015.068614

Jaradat, R. M., Adams, F., Abutabenjeh, S., \& Keating, C. (2017a). The Complementary Perspective of System of Systems in Collaboration, Integration, and Logistics: A Value-Chain Based Paradigm of Supply Chain Management. Systems, 5(4), 50. https://doi.org/10.3390/systems5040050

Jaradat, R. M., Keating, C. B., \& Bradley, J. M. (2017b). Individual capacity and organizational competency for systems thinking. IEEE Systems Journal. https://doi.org/10.1109/JSYST.2017.2652218

Jung, C. G. (1921). Psychological Types. New Jersey: Princeton University Press.

Kunnan, A. J. (1994). Modelling relationships among some test-taker characteristics and performance on EFL tests: An approach to construct validation. Language Testing, 11(3), 225-250. https://doi.org/10.1177/026553229401100301 
Lawrence, G. (1994). People Types and Tiger Stripes. Gainesville, FL. Center for Application of Psychological Type.

Lowie, W., van Dijk, M., Chan, H., \& Verspoor, M. (2017). Finding the key to successful L2 learning in groups and individuals. Studies in Second Language Learning and Teaching, 7(1), 127-148. https://doi.org/10.14746/ss1lt.2017.7.1.7

Myers, I. B., McCaulley, M. H., Quenk, N. L., \& Hammer, A. L. (1998). MBTI manual: A guide to the development and use of the Myers-Briggs Type Indicator (Vol. 3). Palo Alto, CA: Consulting Psychologists Press.

Nagahi, M., Nagahisarchoghaei, M., Soleimani, N., \& Jaradat, R. M. (2018). Hedge Strategies of Corporate Houses. Journal of Business Administration Research, 7(1), 6. https://doi.org/10.5430/jbar.v7n1p6

Nosratinia, M. (2011). The effect of personality type, learning styles, and strategies on Iranian MA EFL learners. Islamic Azad university, Central-Tehran Branch, Tehran-Iran.

Pawlak, M. (Ed.). (2012). New perspectives on individual differences in language learning and teaching. Springer Science \& Business Media. https://doi.org/10.1007/978-3-642-20850-8

Paulhus, D. L., \& Reid, D. B. (1991). Enhancement and denial in socially desirable responding. Journal of Personality and Social Psychology, 60(2), 307. https://doi.org/10.1037/0022-3514.60.2.307

Phakiti, A. (2003). A closer look at the relationship of cognitive and metacognitive strategy use to EFL reading achievement test performance. Language testing, 20(1), 26-56. https://doi.org/10.1191/02655322031t243oa

Purpura, J. E. (1997). An analysis of the relationships between test takers' cognitive and metacognitive strategy use and second language test performance. Language Learning, 47(2), 289-325. https://doi.org/10.1111/0023-8333.91997009

Rashtchi, M., \& Afzali, M. (2011). Spoken grammar awareness raising: Does it affect the listening ability of Iranian EFL learners? Studies in Second Language Learning and Teaching, 1(4), 515-531. https://doi.org/10.14746/ssllt.2011.1.4.4

Saches, R. (2009). The Importance of Testing in School. Retrieved online at http://ezinearticles.com/?expert=Ryan_Sachs.

Schwarz, N. (1999). Self-reports: How the questions shape the answers. American Psychologist, 54, 93-105. https://doi.org/10.1037/0003-066X.54.2.93

Song, X., \& Cheng, L. (2006). Language learner strategy use and test performance of Chinese learners of English. Language Assessment Quarterly: An International Journal, 3(3), 243-266. https://doi.org/10.1207/s15434311laq0303_2

Tajedin, Z. (2001). Language learning strategies: A strategy-based approach to L2 learning, strategic competence, and test validation. Unpublished doctoral dissertation. Allameh 
Tabatabaee University, Tehran, Iran. Available online: www.irandoc.ir

Trammell, J. (2016). Utilizing WAIS Scores to Determine Foreign Language Pathways and Learning Assistance for Students with Learning Disabilities Journal of College Reading and Learning, 46(1), 3-15. https://doi.org/10.1080/10790195.2015.1076372 